\title{
Characteristics of mid-latitude planetary waves in the lower atmosphere derived from radiosonde data
}

\author{
R. Wang ${ }^{1,2}$, S. D. Zhang ${ }^{3,4}$, H. G. Yang ${ }^{1}$, and K. M. Huang ${ }^{3,4}$ \\ ${ }^{1}$ SOA Key Laboratory for Polar Science, Polar Research Institute of China, Shanghai, China \\ ${ }^{2}$ State Key Laboratory of Space Weather, Chinese Academy of Sciences, Beijing, China \\ ${ }^{3}$ School of Electronic Information, Wuhan University, Wuhan, China \\ ${ }^{4}$ Key Laboratory of Geospace Environment and Geodesy, Ministry of Education, Wuhan, China
}

Correspondence to: R. Wang (wangrui@pric.gov.cn)

Received: 18 May 2012 - Revised: 20 August 2012 - Accepted: 3 September 2012 - Published: 4 October 2012

\begin{abstract}
The activities of mid-latitude planetary waves (PWs) in the troposphere and lower stratosphere (TLS) are presented by using the radiosonde data from 2000 to 2004 over four American stations (Miramar Nas, $32.9^{\circ} \mathrm{N}$, 117. $2^{\circ} \mathrm{W}$; Santa Teresa, $31.9^{\circ} \mathrm{N}, 106.7^{\circ} \mathrm{W}$; Fort Worth, $32.8^{\circ} \mathrm{N}, 97.3^{\circ} \mathrm{W}$; and Birmingham, $33.1^{\circ} \mathrm{N}, 86.7^{\circ} \mathrm{W}$ ) and one Chinese station (Wuhan, $30.5^{\circ} \mathrm{N}, 114.4^{\circ} \mathrm{E}$ ). Statistically, strong PWs mainly appear around subtropical jet stream in the troposphere and lower stratosphere. In the troposphere, the activities of the mid-latitude PWs are strong around the centre of the subtropical jet stream in winter and become small near the tropopause, which indicates that the subtropical jet stream may strengthen the propagation of PWs or even be one of the PW excitation sources. Among the three disturbance components of temperature, zonal and meridional winds, PWs at Wuhan are stronger in the temperature component, but weaker in the zonal wind component than at the other four American stations. While in the meridional wind component, the strengths of PW spectral amplitudes at the four American stations decrease from west to east, and their amplitudes are all larger than that of Wuhan. However, the PWs are much weaker in the stratosphere and only the lower frequency parts remain. The amplitudes of the PWs in the stratosphere increase with height and are strong in winter with the zonal wind component being the strongest. Using the refractive index, we found that whether the PWs could propagate upward to the stratosphere depends on the thickness of the tropopause reflection layer. In the case study of the 2000/2001 winter, it is observed that the quasi 16-day wave in the troposphere is a quasi standing wave in the vertical direction and propagates upward slowly with vertical
\end{abstract}

wavelength greater than $24 \mathrm{~km}$ in the meridional component. It propagates eastward with the zonal numbers between 5 and 8 , and the quasi 16-day wave at Wuhan is probably the same quasi 16-day wave at the three American stations (Miramar Nas, Santa Teresa and Fort Worth), which propagates steadily along the latitude. The quasi 16-day wave in the stratosphere is also a standing wave with vertical wavelength larger than $10 \mathrm{~km}$ in the zonal wind component, and it is westward with the zonal number 1-2. However, the quasi 16-day wave in the stratosphere may not come from the troposphere because of the different concurrent times, propagation directions and velocities. By using the global dataset of NCEP/NCAR reanalysis data, the zonal propagation parameters of 16-day waves in the troposphere and stratosphere are calculated. It is found that the tropospheric 16-day wave propagates eastward with the zonal number 6 , while the stratospheric 16-day wave propagates westward with the zonal number 2 , which matches well with the results of radiosonde data.

Keywords. Meteorology and atmospheric dynamics (Mesoscale meteorology; Middle atmosphere dynamics; Waves and tides)

\section{Introduction}

Atmospheric waves are found in meteorological parameters, e.g., atmospheric temperature, pressure and wind field. They are observed as wave-like variations of the atmosphere with respect to the mean background state. The atmospheric waves cover a large range of scales from planetary scale (horizontal wavelengths of about $10000 \mathrm{~km}$ or even more) 
over mesoscale $(100-1000 \mathrm{~km})$ to small-scale with horizontal wavelengths of only several $\mathrm{km}$ (one example of mesoand small-scale waves is gravity waves), which are believed to impact on atmospheric climatology significantly (Salby, 1984; Alexander, 1998; Huang et al., 2009). Generally, planetary wave, gravity wave and atmospheric tide are three main atmospheric waves.

Planetary waves (PWs) are quasi-horizontal atmospheric motions, whose shape, wavelength and propagation is controlled by variations of the Coriolis parameter with latitude. These oscillations are mainly excited in the troposphere and propagate out of the troposphere up to the middle atmosphere under certain conditions. They are often global scale waves with integer oscillations in the zonal direction and could play an important role in adjusting middle atmosphere circulation (Andrews et al., 1987). Planetary waves are usually classified by their periods, such as the 2-day, the 5-day, the 10-day and the 16-day waves (e.g., Salby, 1981a, b, 1984). This classification comes from the theoretical derivation although observations confirm plenty variability in these periods, which are sometimes seen to change dynamically with time (Beard et al., 2001). Thus, they are always called quasi 2-day, quasi 5-day, quasi 10-day and quasi 16-day waves, whose periods are about $2-4,4.5-6.2,7.5-12$, and 11-20 days, respectively (Luo et al., 2002a, b).

Jet streams are fast flowing, narrow air currents found in the atmosphere. In the mid-latitude regions, lower atmospheric jet streams are located near the tropopause, and the transition between the troposphere and the stratosphere, because of the strong temperature gradients. Subtropical jet streams appear in the transition zone between the tropical tropopause and mid-latitude tropopause, which is an important feature in the mid-latitudes. They are mainly around $10-15 \mathrm{~km}$ in altitude. The subtropical jet streams are strong in winter with maximum speed exceeding $100 \mathrm{~m} \mathrm{~s}^{-1}$. While they are very weak or even disappear in summer with maximum wind speed only $30-40 \mathrm{~m} \mathrm{~s}^{-1}$. The subtropical jet streams are also an important part of the global atmospheric circulation, which are related to transportation of the atmospheric heat and the angular momentum. Some scholars (Matsuno, 1970; Chen and Huang, 2002) thought subtropical jet could impede the upward propagations of the PWs, and formed a low refractive index zone, making the tropospheric planetary waves propagate upward along the highlatitude and low-latitude waveguides. The intensity of the subtropical jet stream would significantly affect the strength of the two waveguides, thereby affecting the propagations of the planetary waves. Whereas some scholars (Hu and Tung, 2002; Li et al., 2007) thought the jet does not hinder, but enhance the vertical propagations of PWs. Mid-latitude regions, which are considered as global planetary wave sources, could influence propagations of the global planetary waves significantly. Therefore, it is necessary to study the activities of the mid-latitude planetary waves.
Radiosonde is a traditional meteorological method with advantages of high vertical resolution, wide geographical coverage, long-term data accumulation and relatively complete physical quantities. Radiosonde observations are extensively used to help us understand dynamics in the troposphere and lower stratosphere (TLS) (Tsuda et al., 1994a, b, 1997; Allen and Vincent, 1995; Shimizu and Tsuda, 1997; Pfenninger et al., 1999; Vincent and Alexander, 2000; Yoshiki and Sato, 2000; Holton et al., 2001; Vial et al., 2001; Zink and Vincent, 2001a, b; Innis et al., 2004, 2006; Wang and Geller, 2003; Wang et al., 2005, 2010; Seidel et al., 2005; Lu et al., 2005; Seidel and Randel, 2006; Zhang and Yi, 2005, 2007; Zhang et al., 2006, 2008, 2009; Alexander and Tsuda, 2008; Huang et al., 2009). Among them, some scholars focus on the PWs in the mid-latitude (Lu et al., 2005; Huang et al., 2009). Although there are global reanalysis datasets (e.g., NCEP or ECMWF) and GPS radio occultation (e.g., CHAMP or COSMIC) for us to study the characteristics of PWs in the lower atmosphere, radiosonde has its advantages in some aspects. Compared with global reanalysis data, radiosonde has high vertical resolution which makes it easier to show the subtle vertical structures of PWs. Although GPS radio occultation also has high vertical resolution, it cannot provide horizontal wind data.

In this paper, the characteristics of mid-latitudinal PWs in temperature, zonal and meridional winds are simultaneously studied with radiosonde observations of four American stations and one Chinese station. The dataset utilised here is described in detail in the following section. The background atmosphere in the mid-latitude is given in Sect. 3. Both statistical and case studies of PWs are shown in Sects. 4 and 5, respectively. To confirm the results of the zonal propagation parameters estimated from radiosonde data, NCEP/NCAR reanalysis data are studied in Sect. 5.3. In the last section, we give a brief summary of our observations.

\section{Data description}

The data utilised in this paper are from National Climatic Data Center (NCDC) of National Oceanic and Atmospheric Administration (NOAA) in the United States (These data may be freely accessed through the SPARC Data Center at http://www.sparc.sunysb.edu/) and Wuhan Center Station of Meteorology in China. Both of the American and Chinese balloons are released twice a day with the time of 00:00 and 12:00 UTC, recording data of temperature, pressure, zonal and meridional winds, etc. The US raw data are recorded at 6-s intervals, while the Chinese raw data are sampled at 8-s intervals, resulting in an uneven height resolution of several tens of metres. For convenience, the raw data were linear interpolated to be an even height resolution of $100 \mathrm{~m}$. In the American dataset, about $87.4 \%$ of balloon reached the height of $30 \mathrm{~km}$, but only about $30.8 \%$ reached $35 \mathrm{~km}$, whereas at Wuhan Center Station, only about $52 \%$ of measurements 


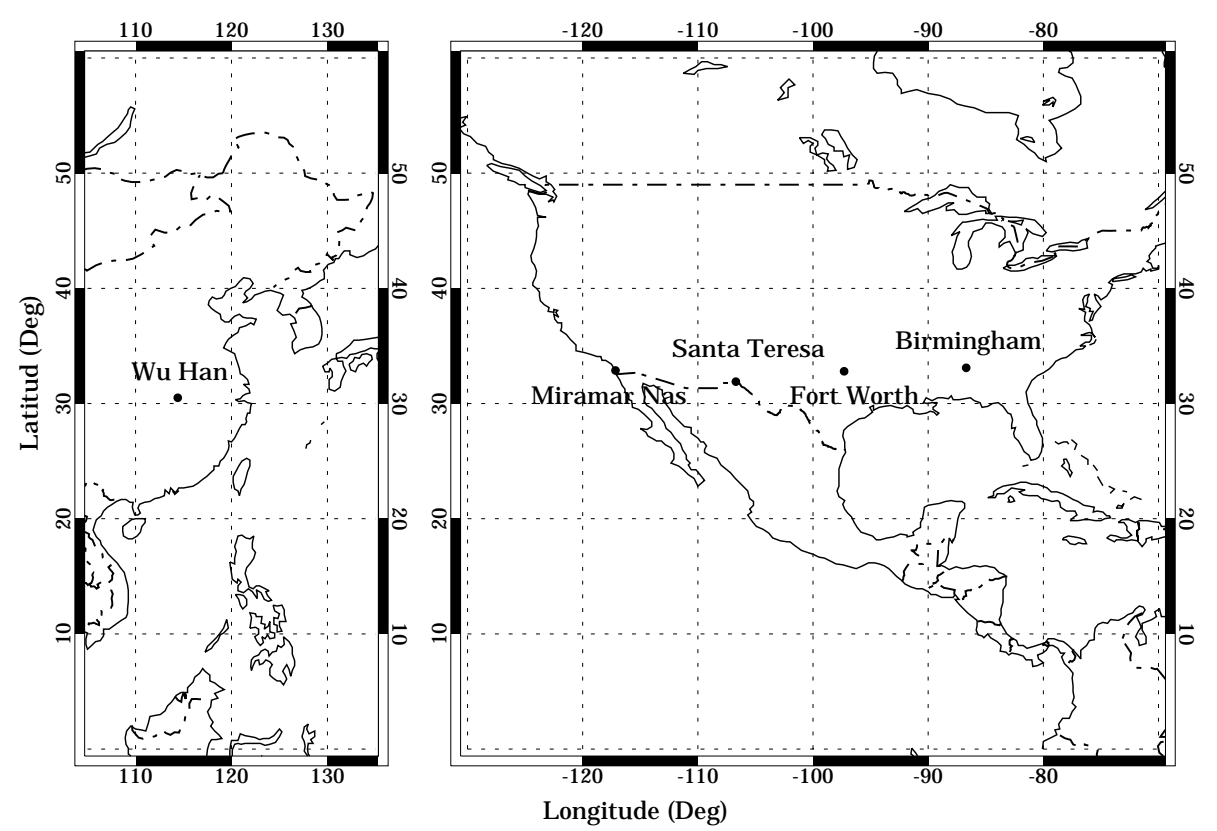

Fig. 1. Geographic locations of the five chosen radiosonde stations.

reached $25 \mathrm{~km}$ and $18 \%$ reached $27 \mathrm{~km}$. Thus, we choose 30 and $25 \mathrm{~km}$ as the upper height limit of American and Chinese dataset for our analysis, respectively. Moreover, considering we could only get radiosonde observational dataset of Wuhan station from 2000 to 2004, the same period observations of American stations are chosen to facilitate comparative analysis.

There are a lot of American radiosonde stations in midlatitude, throughout most of the United States. In order to compare with radiosonde data at Wuhan station $\left(30.5^{\circ} \mathrm{N}\right.$, $114.4^{\circ} \mathrm{E}$ ), four American mid-latitude stations (Miramar Nas, $32.9^{\circ} \mathrm{N}, 117.2^{\circ} \mathrm{W}$; Santa Teresa, $31.9^{\circ} \mathrm{N}, 106.7^{\circ} \mathrm{W}$; Fort Worth, $32.8^{\circ} \mathrm{N}, 97.3^{\circ} \mathrm{W}$; and Birmingham, $33.1^{\circ} \mathrm{N}$, $86.7^{\circ} \mathrm{W}$ ) are chosen because their latitudes are close to Wuhan. Moreover, the four American stations are apart nearly $10^{\circ}$ in longitude, which could help analyse the characteristics in longitude. Their geographic locations are illustrated in Fig. 1. From 2000 to 2004, expect October and November 2003 for Miramar Nas and April 2002 for Santa Teresa, available observations are more than $2 / 3$ of the whole month routine observations in every month.

\section{Background atmosphere}

The PW activities are closely related to the background structure, so the seasonal variability of background atmosphere is investigated first. Figure 2 shows the monthly-averaged temperature and winds from 2000 to 2004 (the gap is caused by the lack of observation data). The solid lines in the top panels denote the tropopause that is defined as coldest point, and the solid lines in the middle and bottom panels denote the zero wind velocity.

In the troposphere, the temperature exhibits an annual oscillation with the Sun cycle, which is high in summer and low in winter. Similar variation also happens in the lower stratosphere. The heights of the tropopause are between $15 \mathrm{~km}$ and $20 \mathrm{~km}$ at four American stations, and they are higher in winter than in summer. However, the variation of the tropopause height at Wuhan is smaller with slight fluctuation around $17 \mathrm{~km}$. Furthermore, the temperature of the tropopause is also high in winter and low in summer, and the minimal temperature is below $-70^{\circ} \mathrm{C}$.

The zonal wind is generally small below $3 \mathrm{~km}$. In the height of $3-20 \mathrm{~km}$, the zonal wind is mainly eastward. The wind velocity usually increases to about $12 \mathrm{~km}$ and then decreases with height. The maximum velocity is at round $12 \mathrm{~km}$ in winter, which indicates a strong subtropical jet stream in winter. At Wuhan, the strongest wind is $75.9 \mathrm{~m} \mathrm{~s}^{-1}$, while at four American stations, the strongest winds increase from west to east with the peak speeds of $39.6 \mathrm{~m} \mathrm{~s}^{-1}, 43.6 \mathrm{~m} \mathrm{~s}^{-1}$, $45.1 \mathrm{~m} \mathrm{~s}^{-1}$ and $57.9 \mathrm{~m} \mathrm{~s}^{-1}$, respectively, which is because there are three eastward wind maxima areas at mid-latitude region (south of Japan, Saudi Arabia-Egypt and the east coast of the United States) (Yang et al., 2002). The zonal wind near tropopause becomes small. In the lower stratosphere, the zonal wind increases with height, and the wind is westward from May to October and eastward in the other half of the year, which is consistent among the five stations. The maximum westward and eastward winds could both exceed $25 \mathrm{~m} \mathrm{~s}^{-1}$. Although the variation of meridional wind is also annual, it is weaker than zonal wind. In the 

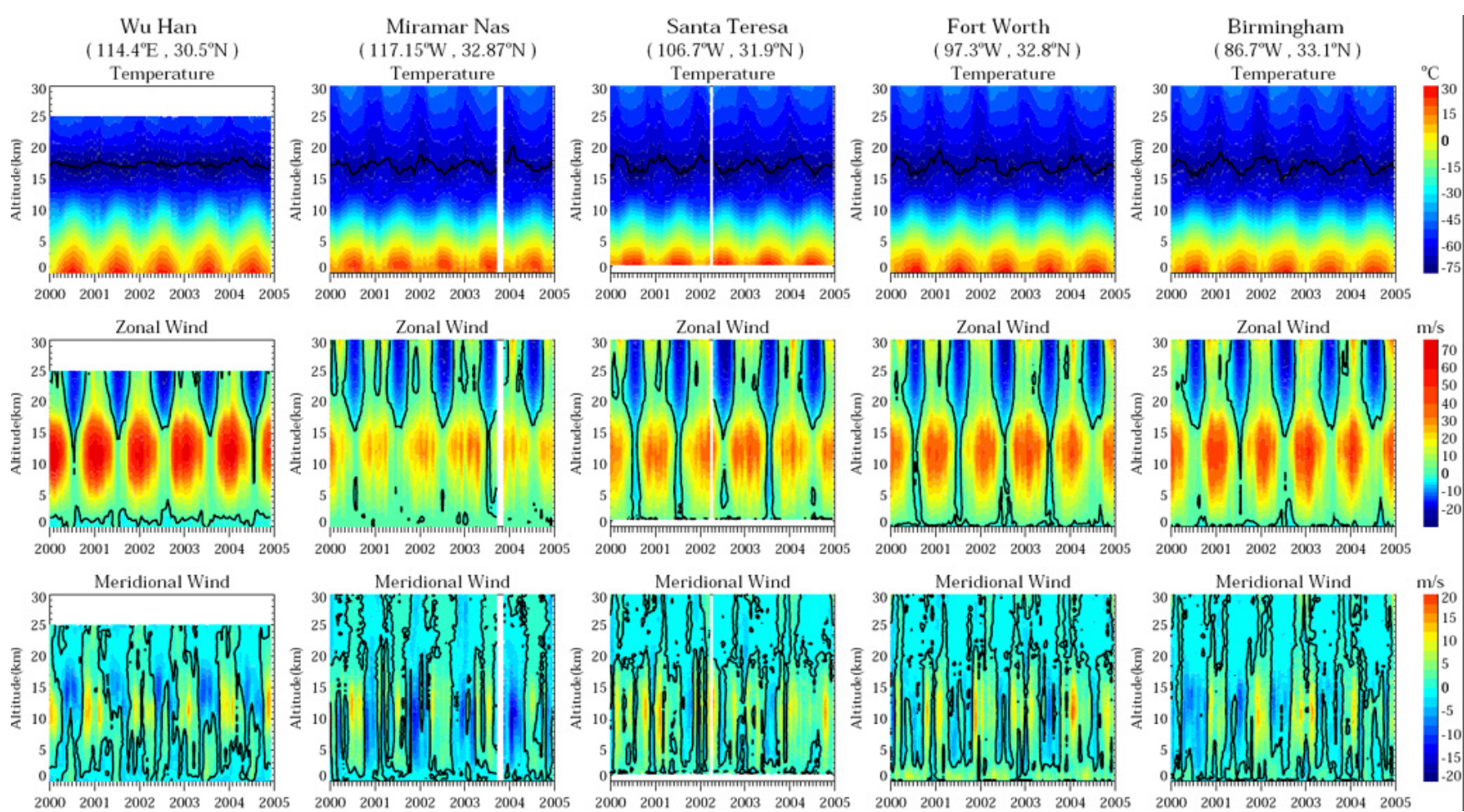

Fig. 2. Time-height cross-sections of the background temperature (top), zonal (middle) and meridional (bottom) winds during 2000-2004. The solid lines denote the coldest point of temperature (top) and wind velocity of $0 \mathrm{~m} \mathrm{~s}^{-1}$ (middle and bottom).

height of 5-20 km, it frequently alters its direction with dominant northward wind in winter and southward wind in summer. The maximum velocity occurs around $12 \mathrm{~km}$ with approximate value of $20 \mathrm{~m} \mathrm{~s}^{-1}$. Generally speaking, the midlatitudinal climatological features between the east and west hemispheres are basically the same.

\section{Statistical results}

\subsection{Wave periods at subtropical jet stream}

Since planetary waves come from the troposphere and subtropical jet stream is a prominent feature in the lower atmosphere in mid-latitude area, we select the height of $10 \mathrm{~km}$ to analyse the activities of PWs at subtropical jet stream. In order to investigate the seasonal variability of PWs, a 30day running window shifted 15-day increments is adopted. In each window, the background data are calculated by lowpass filter with cut-off frequency corresponding to a period of 20 days, since general PW periods are less than 20 days (Salby, 1984; Beard et al., 2001). The disturbance data can be calculated by subtracting the background data from the raw data, and then used to obtain the normalised power spectra $P_{N}(\omega)$ of PWs with the Lomb-Scargle periodogram method (Lomb, 1976; Scargle, 1982). At last, the normalised power spectra are changed to the corresponding wave ampli- tude $A_{N}(\omega)=2 \sigma \sqrt{\frac{P_{N}(\omega)}{N}}$ (Allen and Vincent, 1995; Hocke, 1998 ), where $\omega$ is the wave frequency, $N$ is number of data point, $\sigma$ is the squared variance of data. The Lomb-Scargle spectral amplitudes at the five stations are shown in Fig. 3. It is found that the activities of PWs are discontinuous and their life time is usually less than two months (Mitchell et al., 1999; Beard et al., 2001). However, there are exceptions. For example, a strong 10-day wave in the zonal wind component at Wuhan exists from December 2001 to April 2002, and a strong 16-day wave in the meridional wind component at Fort Worth also appears nearly half a year from December 2000 to May 2001. It indicates that planetary waves may persist in the lower atmosphere for a long time. Large PWs prefer to appear in winter with the strong eastward zonal background wind (see Fig. 2), which means strong eastward winds may strengthen rather than block the propagation of planetary waves (Hu and Tung, 2002; Li et al., 2007).

Although 5-, 10-, and 16-day waves all exist at the five stations, the low-frequency planetary waves are stronger. The peak value of temperature spectral amplitude is $4.8 \mathrm{~K}$, while the peak amplitudes for the zonal and meridional wind components are $17.8 \mathrm{~m} \mathrm{~s}^{-1}$ and $19.9 \mathrm{~m} \mathrm{~s}^{-1}$, respectively. However, there are some differences among the five stations. In the temperature component, the low-frequency planetary waves are stronger and more common at Wuhan than at the four American stations. However, the planetary waves in the zonal wind component at Wuhan are the weakest. 

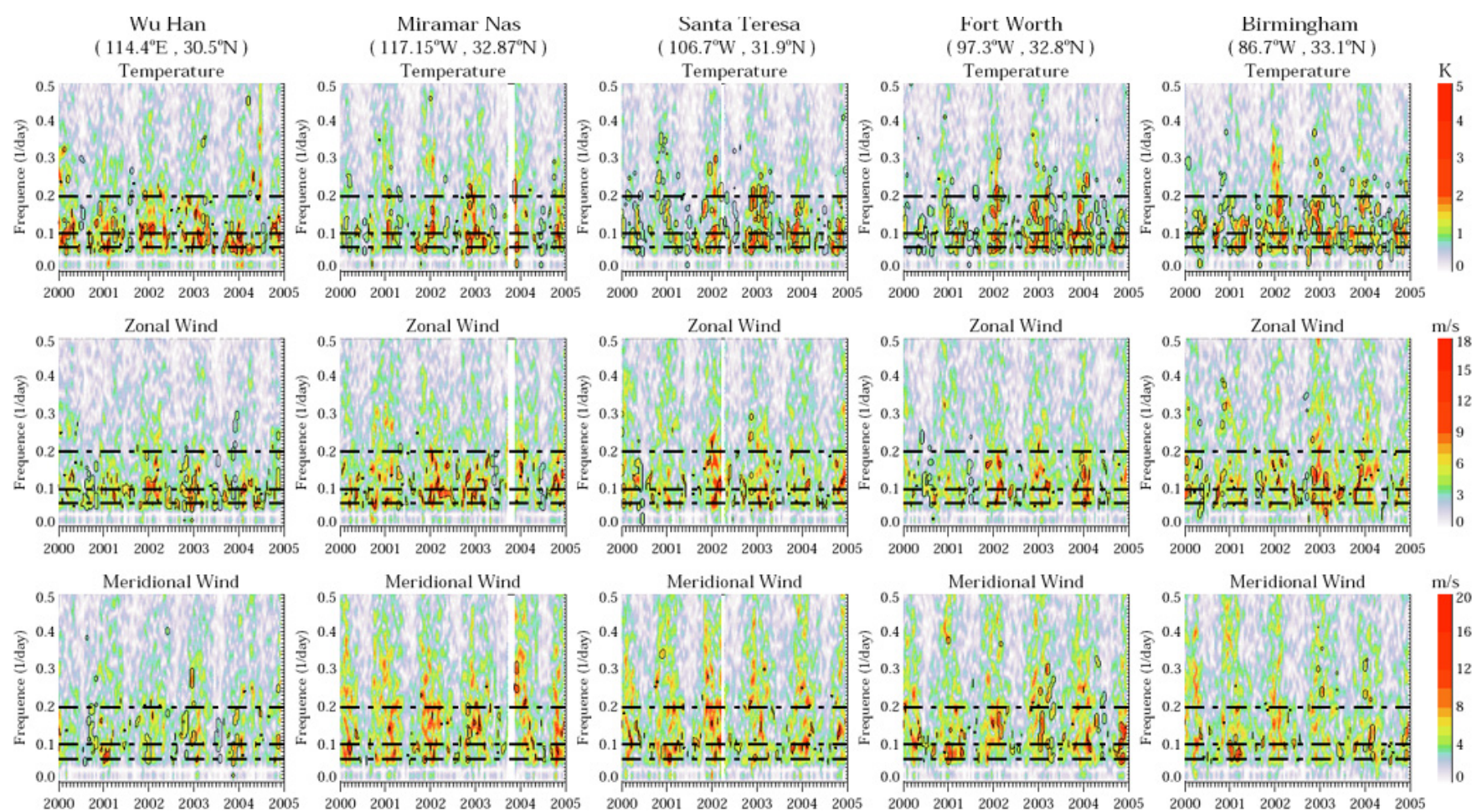

Fig. 3. Time-frequency cross-sections of the Lomb-Scargle spectral amplitudes of the temperature, zonal and meridional wind disturbances at $10 \mathrm{~km}$ during 2000-2004. The dash-dotted lines in every panel denote the frequencies of the 5-, 10- and 16-day waves, respectively, from up to down. The significance of $90 \%$ confidence level is shown with black contour.

As to meridional wind component, the spectral amplitude at Wuhan is the smallest with the peak value of $13.8 \mathrm{~m} \mathrm{~s}^{-1}$. The amplitudes at the four American stations decrease from west to east and their maximum values are $19.9 \mathrm{~m} \mathrm{~s}^{-1}, 19.7 \mathrm{~m} \mathrm{~s}^{-1}$, $18.3 \mathrm{~m} \mathrm{~s}^{-1}$ and $15.7 \mathrm{~m} \mathrm{~s}^{-1}$, respectively.

\subsection{The seasonal and vertical structures}

Although the activities of planetary waves at $10 \mathrm{~km}$ are shown in Sect. 4.1, it is difficult for us to learn the activities at other altitudes. By applying the harmonic analyses, we could get the amplitudes and phases of PWs with a specific period at every height in each 30-day running and 15-day sliding window. Figure 4 demonstrates the amplitudes of 5-, $10-$, and 16-day waves over Fort Worth Station from 2000 to 2004. It could be found that planetary waves mainly appear among the altitude of 3-20 km with no obvious seasonal variation. In addition, planetary waves could also be found in the zonal wind component above $20 \mathrm{~km}$ in winter. The standard deviations of amplitude are less than $0.53 \mathrm{~K}$ (temperature), $0.53 \mathrm{~m} \mathrm{~s}^{-1}$ (zonal wind) and $0.51 \mathrm{~m} \mathrm{~s}^{-1}$ (meridional wind), and most of them are less than $0.28 \mathrm{~K}^{(\text {or m s}}{ }^{-1}$ ) (not shown).

In the height of 3-20 km, PWs could be found all around the year while strong PWs generally appear in winter. The amplitudes of PWs usually increase with height up to about $12 \mathrm{~km}$, with peak values about $6.3 \mathrm{~K}$ (temperature),
$19.5 \mathrm{~m} \mathrm{~s}^{-1}$ (zonal wind) and $17.8 \mathrm{~m} \mathrm{~s}^{-1}$ (meridional wind), and then decrease with height, which is consist with the change tendency of eastward zonal wind. It is known that planetary waves are mainly excited in the troposphere (Salby, 1984), and the subtropical jet stream in the troposphere is so strong in winter that it could probably be an important source of PWs (Hu and Tung, 2002; Li et al., 2007). Among three different periodic PWs, the quasi 10-day wave is as strong as the quasi 16-day wave, while the quasi 5-day wave is weaker than quasi 10-day and 16-day waves. Moreover, there is a remarkable quasi 16-day wave in the 2000/2001 winter. It is worth noting that, the temperature amplitude suddenly decreases at the altitude of wind amplitude maximum, which is similar to the situation in high-altitude (Wang et al., 2010).

Above $20 \mathrm{~km}$, strong PWs appear mainly in winter, and the amplitude in zonal wind component is much larger than in the meridional wind component, while the amplitude in the temperature component is also not significant as near the subtropical jet stream. Thus, it seems that in the stratosphere, the higher altitude, the activities of PWs are not consistent among the three components, and large PWs mainly exist in the zonal wind component. Between 20 and $30 \mathrm{~km}$, the amplitudes increase with height, and the peak value are $5.8 \mathrm{~K}$ (temperature), $19.5 \mathrm{~m} \mathrm{~s}^{-1}$ (zonal wind) and $7.6 \mathrm{~m} \mathrm{~s}^{-1}$ (meridional wind), respectively. The zonal wind in this range of height is weak eastward in winter and westward in summer 

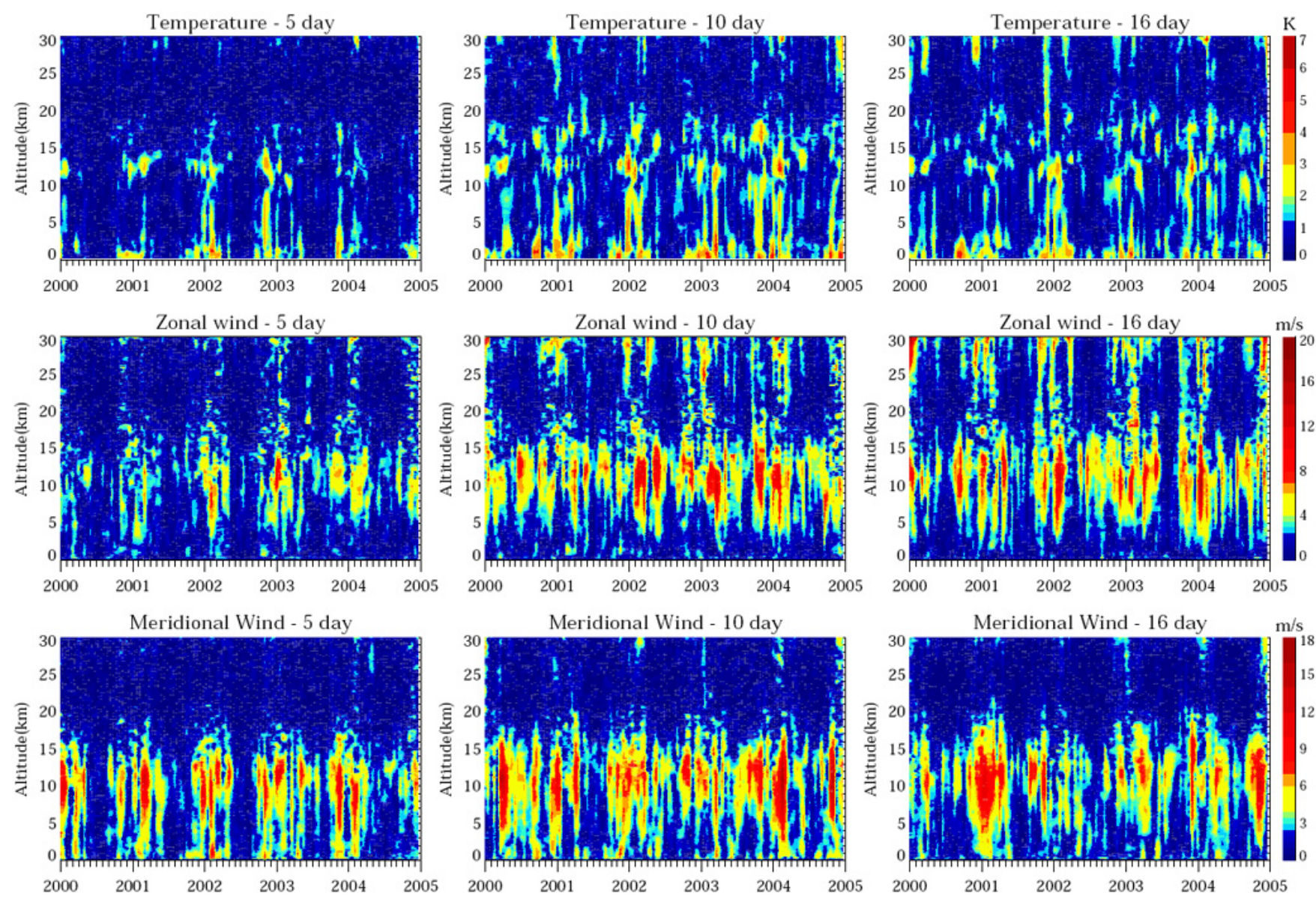

Fig. 4. Time-height cross-sections of the harmonic fitting amplitudes of 5-, 10-, and 16-day waves in the disturbances of the temperature, zonal and meridional winds over Fort Worth Station during 2000-2004.

(see Fig. 2), which means PWs could propagate upward freely in winter and be inhibited in summer (Dickinson, 1968; Matsuno, 1970). Among the three different period PWs, only lower frequency waves exist. The amplitude of the quasi 16-day wave is larger than quasi 10-day wave, while quasi 5-day wave almost disappears, which indicates that it is hard for the 5-day wave to penetrate into the stratosphere. Since similar situation exists in the other four stations, we do not present the results at those stations here.

\subsection{Refractive index}

According to the vertical structures of the PWs presented above, strong PWs mainly exist around the subtropical jet stream and in the stratosphere (above $20 \mathrm{~km}$ ) in winter. Since the propagations of PWs are closely related to the background atmosphere, the refractive index (Charney and Drazin, 1961) is calculated here to reveal the dependence. Refractive index can be expressed by the value of $v^{2}$ as follows:

$v^{2}=4 H^{2} n^{2}$ where,

$$
\begin{aligned}
n^{2}= & -\left\{\frac{\left(k^{2}+l^{2}\right) N^{2}}{f_{0}^{2}}+\sqrt{\frac{N^{2}}{\bar{\rho}}} \frac{d^{2}}{d z^{2}} \sqrt{\frac{\bar{\rho}}{N^{2}}}\right\} \\
& +\frac{N^{2}}{u_{0}-c}\left\{\frac{\beta}{f_{0}^{2}}-\frac{1}{\bar{\rho}} \frac{d}{d z}\left(\frac{\bar{\rho}}{N^{2}} \frac{d u_{0}}{d z}\right)\right\}
\end{aligned}
$$

Here, $\bar{\rho}$ is basic state density, $u_{0}$ is the mean zonal wind, $c$ is phase velocity, $H$ is scale height, $f_{0}$ is Coriolis parameter, $N$ is buoyancy frequency, $\beta$ is Rossby parameter, and $k$ and $l$ are the zonal and meridional wavenumbers, respectively. The wavenumbers $k$ and $l$ can be calculated by the zonal wave number $m$ and the meridional index $n$ (derived from Hough functions) and corresponding latitude and longitude perimeters. Here we choose the normal modes $(m, n)$ of $(1,2),(1,3),(1,4)$ to represent 5-day, 10-day, and 16-day waves (Salby, 1984).

The refractive index squared $v^{2}$ over Fort Worth Station is shown in Fig. 5. Since the variations of the refractive index squared $v^{2}$ at the other four stations are similar, they are not shown here. From Fig. 5, four regions where the refractive 

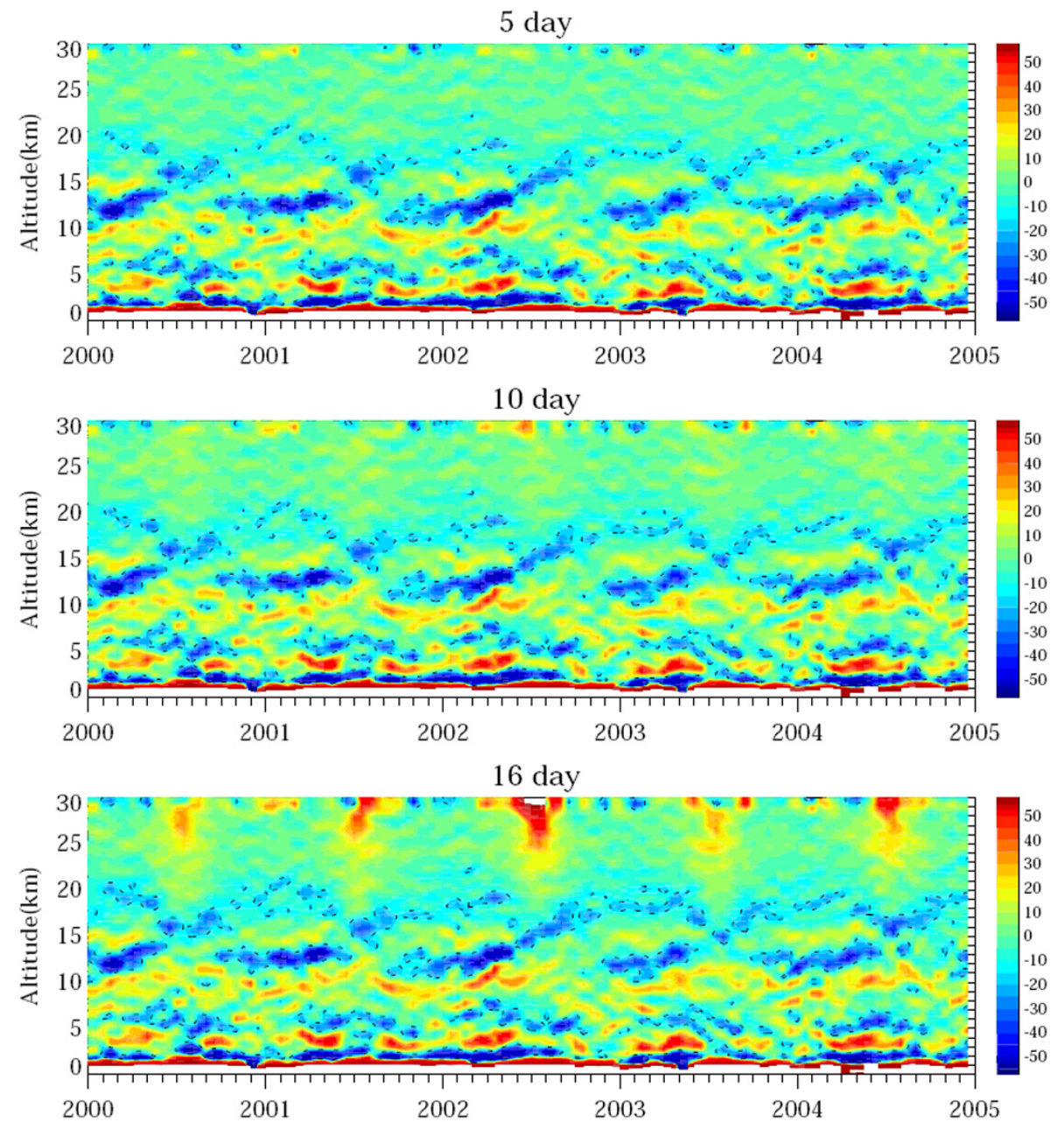

Fig. 5. Time-height cross-sections of refractive index squared $v^{2}$ of quasi 5-, 10- and 16-day waves over Fort Worth Station during 20002004.

index squared $v^{2}$ is negative are shown: two in the lower troposphere (below $5 \mathrm{~km}$ ) and the other two are near the subtropical jet stream and tropopause, respectively.

Within the height region of $2-3 \mathrm{~km}, v^{2}$ is almost negative all year round which indicates there is a reflection layer. The reflection layer exists robustly in most seasons except winter, when the layer is weaker or even disappears. Furthermore, its height basically does not change. There is another relatively weak reflection layer near $5 \mathrm{~km}$, which is thick in summer and disappears in winter. This reflection layer drops to lower altitude in spring/autumn with its strength weakening. Between the two lower troposphere reflection layers, $v^{2}$ is positive. The formation of the two reflection layers may be related with lower tropospheric temperature inversion layers (Nodzu et al., 2006; Zhang et al., 2009).

Near the height of $12 \mathrm{~km}, v^{2}$ reaches negative maximum in winter, where is the centre of the subtropical jet stream (see Fig. 1). According to the classical planetary wave propagation theory (Charney and Drazin, 1961), strong eastward wind will hinder PWs propagation upward. Between $15 \mathrm{~km}$ and $20 \mathrm{~km}$, there is the fourth $v^{2}$ negative region which is much thinner. The height of this $v^{2}$ negative region varies significantly annually, which is high in winter and low in summer, matching with variation of the tropopause (see Fig. 1). And it is thicker in summer than in other seasons. Therefore, it seems the structure of tropopause will also impede the propagation of PWs. In the equation of refractive index, the buoyancy frequency squared is an important factor which depends on temperature gradient, so temperature inversion (including tropopause) may impact the propagation of PWs (Chen and Robinson, 1992; Li et al., 2007).

In Fig. 4, strong PWs appear between $3 \mathrm{~km}$ and $20 \mathrm{~km}$ with amplitude maximum near subtropical jet stream, which are just between the temperature inversion reflection layer of 2$3 \mathrm{~km}$ and tropopause reflection layer, therefore, the PWs are much easier to be reflected between the two reflection layers to form standing waves. Huang et al. (2009) also found the structure of standing planetary wave in TLS at mid-latitude. 

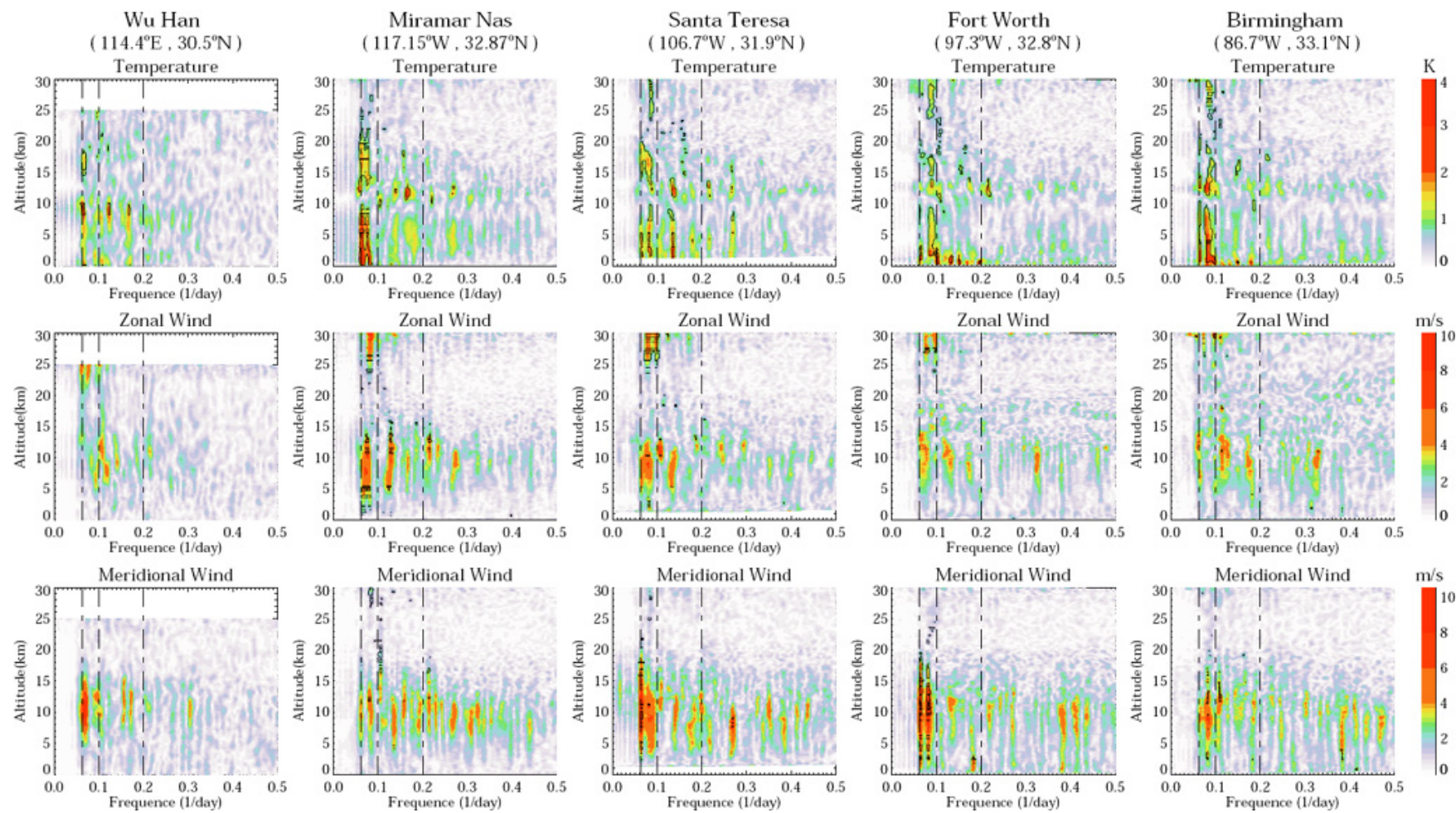

Fig. 6. The Lomb-Scargle spectral amplitudes of the temperature, zonal and meridional wind disturbances during December 2000 to February 2001. The dash-dotted lines in every panel denote the frequencies of the 16-, 10-, and 5-day waves, respectively, from left to right. The significance of $90 \%$ confidence level is shown with black contour.

In addition, although the refractive index squared $v^{2}$ is negative at the centre of subtropical jet stream (near $12 \mathrm{~km}$ ) in winter, the propagation of PWs are not impeded but strengthened, which indicates subtropical jet stream would not prevent the propagation of PWs and may even be an excitation source of PWs (Hu and Tung, 2002; Li et al., 2007).

Above $20 \mathrm{~km}$, the refractive index squared $v^{2}$ is apparently different among the three periods of PWs. In this region, $v^{2}$ is positive, and its value is larger when the frequency of the PWs is lower, which means PWs with lower frequency are easier to propagate upward above $20 \mathrm{~km}$. This phenomenon is prominent in summer. However, there are seldom PWs in summer among this region (see Fig. 4). Strong PWs with lower frequency only appear in zonal wind component in winter. A possible explanation is: The tropopause reflection layer is thin in winter which makes it easier for lower frequency PWs to propagate up into stratosphere, but in summer, the tropopause reflection layer becomes much thicker, and subtropical jet stream, the possible excitation source, disappears, so even the condition is suitable for propagation of PWs, seldom PWs are found in summer in the stratosphere.

Similar results are shown at the other four stations while a few differences exist below $5 \mathrm{~km}$, which may be caused by the local topography and environment. For example, Santa Teresa is located in the Pacific coast. Under the influence of maritime climate, there are strong lower tropospheric tem- perature inversions. Therefore, the reflection layer below $5 \mathrm{~km}$ is very thick at Santa Teresa Station. But overall, the characteristics of reflection layers below $5 \mathrm{~km}$ are similar among all the stations, so the differences of PW basic features are not apparent.

\section{The winter of $2000 / 2001$}

\subsection{Wave amplitudes}

In Sect. 4.2, a strong quasi 16-day wave could be found in the 2000/2001 winter over Fort Worth Station. Hence, we choose the 2000/2001 winter to study the planetary wave activities at the five stations of Wuhan, Miramar Nas, Santa Teresa, Fort Worth and Birmingham, which are convenient for the analysis of the wave zonal structure because of the similar latitudes. Figure 6 shows the wave amplitudes from December 2000 to February 2001 at the five stations. It is found that, there are quasi 16-day waves in the troposphere and stratosphere, respectively. And the amplitudes for the zonal and meridional wind components are roughly equal in the troposphere. However, the PW activities for the three components are not the same, which are similar to the observation results by other scholars (Luo et al., 2002b; Huang et al., 2009). 

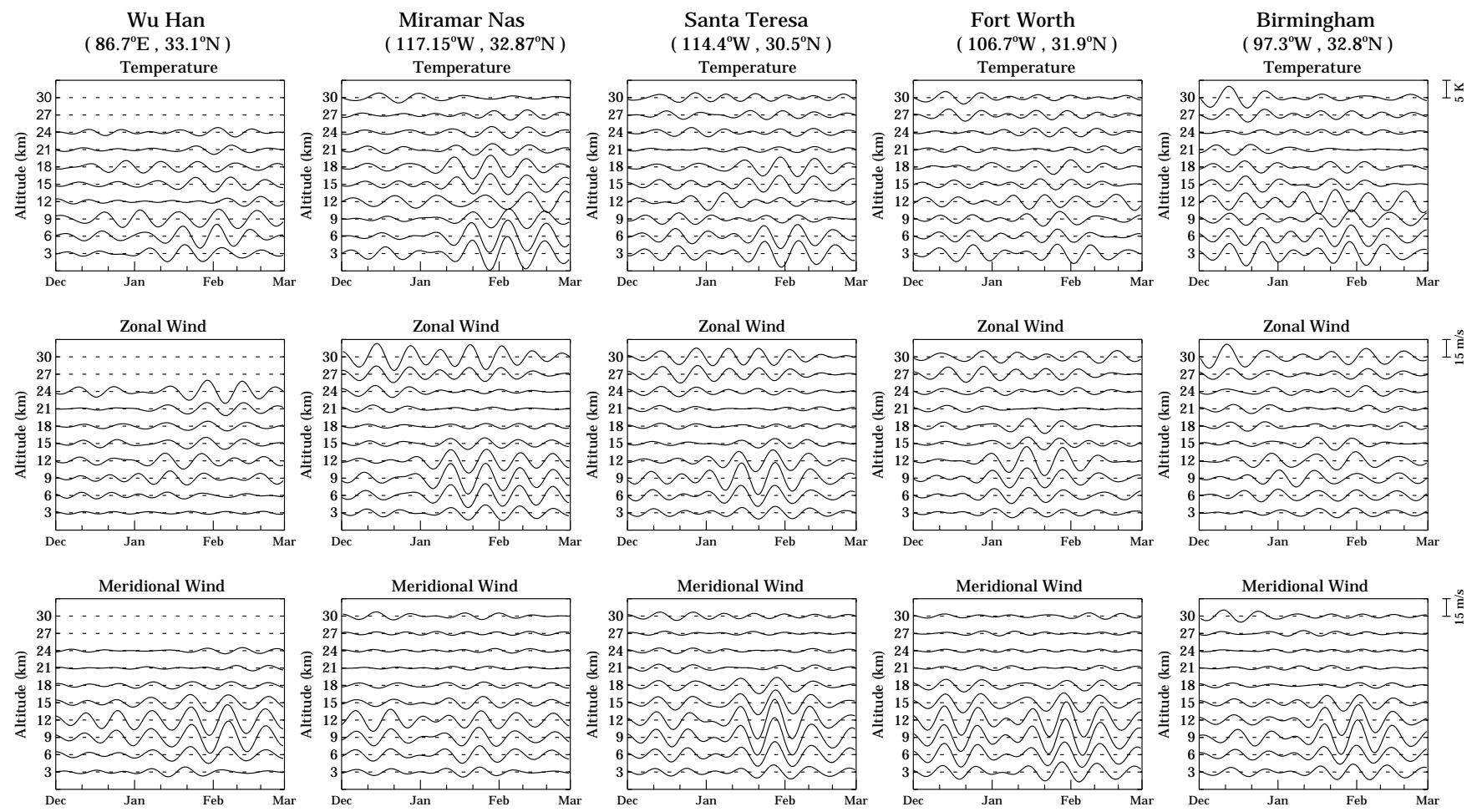

Fig. 7. The band-pass filter results of the temperature, zonal and meridional wind disturbances during December 2000 to February 2001 . The bandwidth is 11-20 day from bottom to $30 \mathrm{~km}$ and the intervals are $5 \mathrm{~K}, 15 \mathrm{~m} \mathrm{~s}^{-1}$, and $15 \mathrm{~m} \mathrm{~s}^{-1}$ for the temperature, zonal and meridional winds, respectively.

In the troposphere $(0-20 \mathrm{~km})$, for the temperature component, strong quasi 16-day wave occurs at Miramar Nas with peak amplitude of $3.9 \mathrm{~K}$, and the quasi 16-day (precisely 12day) wave at Birmingham and Fort Worth exists within 0$15 \mathrm{~km}$ with peak amplitudes of $3.4 \mathrm{~K}$ and $3.2 \mathrm{~K}$, respectively, while no obvious quasi 16-day wave occurs at Wuhan and Santa Teresa among this height range. Besides, the temperature wave amplitudes for the five stations all become small near the centre of subtropical jet stream. For the zonal wind component, there are 12- and 8-day waves at Miramar Nas and Santa Teresa, with peak values reaching $6.7 \mathrm{~m} \mathrm{~s}^{-1}$ and $7.7 \mathrm{~m} \mathrm{~s}^{-1}$ near the centre of the subtropical jet stream. However, the wave amplitude is negligible at Wuhan, Fort Worth and Birmingham. For the meridional wind component, the intense quasi 16-day waves exist at Wuhan, Santa Teresa and Fort Worth with peak amplitude of $9.2 \mathrm{~m} \mathrm{~s}^{-1}, 10.6 \mathrm{~m} \mathrm{~s}^{-1}$ and $9.8 \mathrm{~m} \mathrm{~s}^{-1}$, respectively. Whereas the quasi 16-day (precisely 12-day) wave amplitude of Birmingham is smaller with peak amplitude of $7.3 \mathrm{~m} \mathrm{~s}^{-1}$. There is no obvious quasi 16-day wave at Miramar Nas. Similar to the zonal wind component, the wave amplitudes for meridional wind component also reaches the maximum near the centre of subtropical jet stream. That is to say, at the height where wave amplitudes for wind components maximum, the wave amplitude for temperature component changes to small. This similar situation also occurs at high-latitude region (Wang et al., 2010).
In the stratosphere (above $20 \mathrm{~km}$ ), strong quasi 16-day (precisely 12-day) waves mainly occur in the zonal wind component, and the wave amplitudes increase with height. Among the four American stations, Miramar Nas, Santa Teresa, Fort Worth and Birmingham, peak zonal wind amplitudes are $9.3 \mathrm{~m} \mathrm{~s}^{-1}, 5.3 \mathrm{~m} \mathrm{~s}^{-1}, 6.0 \mathrm{~m} \mathrm{~s}^{-1}$ and $7.1 \mathrm{~m} \mathrm{~s}^{-1}$, respectively. Although the height limit at Wuhan is $25 \mathrm{~km}$, it seems that there is also a strong quasi 16-day wave in the stratosphere.

In order to analysis the time variations of quasi 16-day wave in the troposphere and stratosphere, the disturbances of the temperature, zonal and meridional winds in the height of $0-30 \mathrm{~km}$ are filtered with band-pass filter, and the bandwidth is 11-20 days (Salby, 1984). The band-pass filter results for the five stations are shown in Fig. 7. At Wuhan station, only the result below $25 \mathrm{~km}$ is presented because of the data limitation. In the troposphere, strong quasi 16-day waves could be found in the three components from 10 January 2001 to 28 February 2001. Especially, for the temperature component at Birmingham and the meridional wind component at Wuhan and Fort Worth, quasi 16-day waves last almost the whole three months. It is worth noting that the phases for the temperature component flip $180^{\circ}$ near $12 \mathrm{~km}$. Whereas in the stratosphere, the quasi 16-day wave mainly appears in the zonal wind component, which indicates that the condition for propagation of PWs in the stratosphere are more complex 

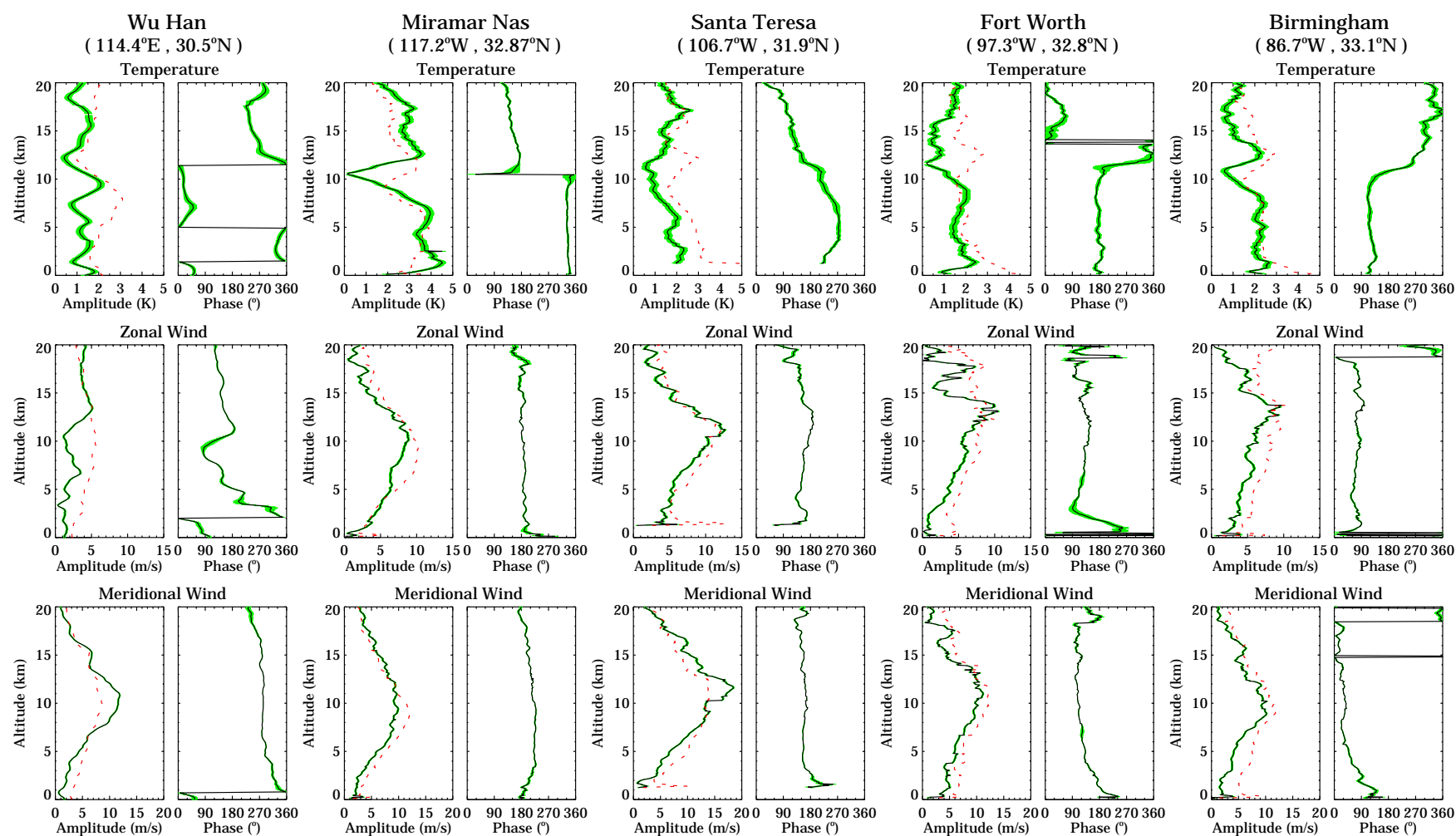

Fig. 8. The harmonic fitting results for the quasi 16-day waves of the temperature, zonal and meridional wind disturbances during 15 January 2001 to 15 February 2001 in the height of 0-20 km. The green lines in every $100 \mathrm{~m}$ in height denote the error bar.

and PWs prefer to exist in the zonal wind component. For the five stations, the activities of quasi 16-day wave are not exactly the same, and they are stronger and more durable at Miramar Nas and Santa Teresa. In addition, although Wuhan is far away from the four American stations, similar activities of PWs are found, which illustrates the planetary waves could probably propagate along the zonal direction steadily.

\subsection{The vertical structures and zonal propagations}

In the troposphere, the quasi 16-day waves for the three components simultaneously exist from 15 January 2001 to 15 February 2001. Therefore, we select this period to study the vertical structure and zonal propagation in the troposphere. Figure 8 shows the results of the harmonic fitting. In each pair panels, the solid lines are the amplitude profile on the left panel and the phase profile on the right panel, and the red dotted line on the left panel denotes the confidence level of $90 \%$ in the Lomb-Scargle periodogram analysis.

For the temperature component, the confidence is high at Miramar Nas, and its amplitude becomes peak at $1.3 \mathrm{~km}$, $6.4 \mathrm{~km}$ and $12.5 \mathrm{~km}$ with peak values $4.5 \mathrm{~K}, 4.0 \mathrm{~K}$ and $3.6 \mathrm{~K}$, respectively. The confidence level also exceeds $90 \%$ between $7 \mathrm{~km}$ and $9 \mathrm{~km}$ at Fort Worth and Birmingham. Moreover, among the height range where the confidence level exceeds $90 \%$, the phases at the three stations are almost con- stant, and just decrease slightly with height. In addition, the amplitudes at the three stations become small near $11 \mathrm{~km}$ with their phases jump half period. As for the zonal wind component, the confidence is higher at Santa Teresa and its peak amplitude is $12.6 \mathrm{~m} \mathrm{~s}^{-1}$ at $11 \mathrm{~km}$. The amplitude also reaches maximum at $11 \mathrm{~km}$ with peak value of $10.2 \mathrm{~m} \mathrm{~s}^{-1}$ at Miramar Nas and its phase is almost unchanged in the whole height. As to the meridional wind component, the confidences at Wuhan, Miramar Nas and Santa Teresa all exceed $90 \%$ in the height of $6-17 \mathrm{~km}, 11-20 \mathrm{~km}$ and 10 $20 \mathrm{~km}$, respectively. And their amplitudes reach maximum near $11 \mathrm{~km}$ as well with peak values of $11.9 \mathrm{~m} \mathrm{~s}^{-1}, 9.9 \mathrm{~m} \mathrm{~s}^{-1}$ and $18.5 \mathrm{~m} \mathrm{~s}^{-1}$, respectively. Although the confidences at Fort Worth and Birmingham are not high, their maximum amplitudes are also larger than $10 \mathrm{~m} \mathrm{~s}^{-1}$. Besides, the phases at the five stations slightly decrease with height. This indicates that the quasi 16-day waves are quasi standing wave in the vertical direction and just slowly propagate upward. The amplitudes at the five stations are all large, and their phases present the similar structure. The maximum standard deviations of amplitude are $0.19 \mathrm{~K}$ (temperature), $0.44 \mathrm{~m} \mathrm{~s}^{-1}$ (zonal wind) and $0.37 \mathrm{~m} \mathrm{~s}^{-1}$ (meridional wind), while the maximum standard deviations of phase are $45.1^{\circ}$ (temperature), $27.0^{\circ}$ (zonal wind) and $12.3^{\circ}$ (meridional wind).

Considering only some amplitudes in the temperature and zonal wind components are credible, we choose the 
Table 1. Propagation parameters of quasi 16-day wave for meridional wind component in troposphere.

\begin{tabular}{lcccc}
\hline Stations & Phase difference & Zonal distance & Propagation velocity & Wave number \\
\hline Miramar Nas-Santa Teresa & $57.8^{\circ}$ & $991.6 \mathrm{~km}$ & $4.5 \mathrm{~m} \mathrm{~s}^{-1}$ & 5.5 \\
Miramar Nas-Fort Worth & $103.3^{\circ}$ & $1856 \mathrm{~km}$ & $4.7 \mathrm{~m} \mathrm{~s}^{-1}$ & 5.2 \\
Miramar Nas-Birmingham & $184.8^{\circ}$ & $2834 \mathrm{~km}$ & $4.0 \mathrm{~m} \mathrm{~s}^{-1}$ & 6.1 \\
Santa Teresa-Fort Worth & $45.5^{\circ}$ & $888.4 \mathrm{~km}$ & $5.1 \mathrm{~m} \mathrm{~s}^{-1}$ & 4.8 \\
Santa Teresa-Birmingham & $137.0^{\circ}$ & $1878 \mathrm{~km}$ & $3.6 \mathrm{~m} \mathrm{~s}^{-1}$ & 6.9 \\
Fort Worth - Birmingham & $81.5^{\circ}$ & $989.2 \mathrm{~km}$ & $3.2 \mathrm{~m} \mathrm{~s}^{-1}$ & 7.7 \\
\hline
\end{tabular}

meridional wind amplitudes and phases to estimate the parameters of the quasi 16-day wave. Because the meridional wind amplitudes reach maximum near $11 \mathrm{~km}$, and the amplitudes are large and the phases change slightly among 5$17 \mathrm{~km}$, the vertical wavelength is greater than $24 \mathrm{~km}$ according to the standing wave theory. In Sect. 4.3, there are lower troposphere reflection layer and tropopause reflection layer which make it easier for the planetary waves to be reflected to form standing waves. The mean phases between $5 \mathrm{~km}$ and $17 \mathrm{~km}$ at the five stations are $280.1^{\circ}, 215.8^{\circ}, 158.0^{\circ}, 112.5^{\circ}$ and $31.0^{\circ}$ from left to right. Considering Wuhan is far away from the four American stations, we first analyse the wave propagation features among the American stations. Since the phases decrease from west to east, the quasi 16-day wave moves eastward. The wave velocity and the zonal wave number are calculated and shown in Table 1.

The adjacent phase differences for Miramar Nas-Santa Teresa and Santa Teresa-Fort Worth are similar, about $50^{\circ}$, but the adjacent phase difference for Fort Worth-Birmingham is $81.5^{\circ}$, with the result of parameters including Birmingham much different from without. Moreover the conference level at Birmingham is low, so the result for the quasi 16-day wave is estimated from the parameters among Miramar Nas, Santa Teresa and Fort Worth. From Table 1, the zonal wave number is about 5 , and propagation velocity is about $5 \mathrm{~m} \mathrm{~s}^{-1}$. With this zonal propagation velocity, the phase for quasi 16-day wave reaching Wuhan is $282^{\circ}$, which match the harmonic fitting result for Wuhan. It indicates that the quasi 16-day wave found at Wuhan is probably the same quasi 16-day wave at Miramar Nas, Santa Teresa and Fort Worth, and the quasi 16-day wave could propagate along the zonal circle stably. Whereas the zonal wave number between Birmingham and the other three American stations is 6-8, and the corresponding propagation velocity is $3-4 \mathrm{~m} \mathrm{~s}^{-1}$, which shows the activity of planetary wave at Birmingham is different from the other stations. Therefore, during 15 January 2001 to 15 February 2001, the quasi 16-day wave within $0-20 \mathrm{~km}$ is a quasi standing wave in vertical direction and propagates upward slowly, with vertical wavelength greater than $24 \mathrm{~km}$ for the meridional wind component. In the zonal direction, the zonal wavenumber is 5 among Wuhan, Miramar Nas, Santa Teresa and Fort Worth, while the activity of quasi 16-day wave is complex at Birmingham, and the zonal wavenumber between Birmingham and the other three American stations is $6-8$.

In the stratosphere, strong quasi 16-day wave mainly exists in the zonal wind component, especially during December 2000, so the zonal wind disturbances above $20 \mathrm{~km}$ are fitted by harmonic analysis with the fitting period of 16 days. Considering the dataset at Wuhan are limited above $20 \mathrm{~km}$, the analysis of the quasi 16-day wave activity is just among the four American stations. The harmonic fitting results within $20-30 \mathrm{~km}$ is shown in Fig. 9.

The amplitudes of the four stations above $25 \mathrm{~km}$ are basically larger than the $90 \%$ confidences and increase with height. The peak values are $9.2 \mathrm{~m} \mathrm{~s}^{-1}, 6.8 \mathrm{~m} \mathrm{~s}^{-1}, 9.5 \mathrm{~m} \mathrm{~s}^{-1}$ and $14.4 \mathrm{~m} \mathrm{~s}^{-1}$ from west to east. And the phases almost stay the same except Miramar Nas decreases slowly. The mean phases between $25 \mathrm{~km}$ and $30 \mathrm{~km}$ are $136.5^{\circ}, 153.1^{\circ}, 173.7^{\circ}$ and $184.4^{\circ}$ from west to east, so the quasi 16-day wave propagate westward. The maximum standard deviations of amplitude and phase are $0.32 \mathrm{~m} \mathrm{~s}^{-1}$ and $6.8^{\circ}$. Because of the lack of the dataset above $30 \mathrm{~km}$, it is difficult to estimate the vertical wavelength. However, the vertical wavelength should be larger than $10 \mathrm{~km}$ according to the structures of phases. The zonal propagation velocity and wavenumber are calculated as that in the troposphere, and the result is $11-24 \mathrm{~m} \mathrm{~s}^{-1}$ (zonal propagation velocity) and 1-2 (wavenumber) which is shown in Table 2.

In addition, although there are quasi 16-day waves both in the troposphere and stratosphere during the winter of 2000/2001, they have many differences. The quasi 16-day wave in the stratosphere mainly occurs in December 2000, while the quasi 16-day wave in the troposphere becomes strong after January 2001. The quasi 16-day wave in the stratosphere propagates westward with wavenumber 1-2, while the quasi 16-day wave in the troposphere propagates eastward with wavenumber 5-8. Moreover, the quasi 16-day wave in the stratosphere is only obvious in the zonal wind component, while in the troposphere, the quasi 16-day wave appears in the three components. Thus, the quasi 16-day wave in the troposphere and the quasi 16-day wave in the stratosphere are not the same one. 

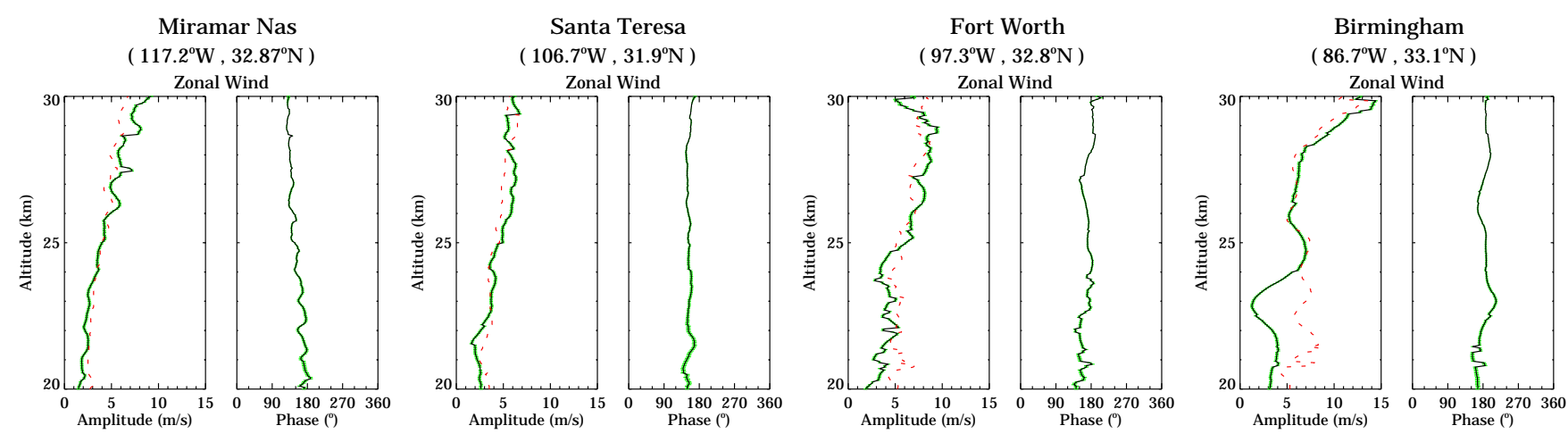

Fig. 9. The harmonic fitting results for the quasi 16-day waves of zonal wind disturbances during December 2000 within $20-30 \mathrm{~km}$. The green lines in every $100 \mathrm{~m}$ in height denote the error bar.

Table 2. Propagation parameters of quasi 16-day wave for zonal wind component in stratosphere.

\begin{tabular}{lcccc}
\hline Stations & Phase difference & Zonal distance & Propagation velocity & Wave number \\
\hline Miramar Nas-Santa Teresa & $16.6^{\circ}$ & $991.6 \mathrm{~km}$ & $15.6 \mathrm{~m} \mathrm{~s}^{-1}$ & 1.6 \\
Miramar Nas-Fort Worth & $37.2^{\circ}$ & $1856 \mathrm{~km}$ & $13.0 \mathrm{~m} \mathrm{~s}^{-1}$ & 1.9 \\
Miramar Nas-Birmingham & $47.9^{\circ}$ & $2834 \mathrm{~km}$ & $15.4 \mathrm{~m} \mathrm{~s}^{-1}$ & 1.6 \\
Santa Teresa-Fort Worth & $20.6^{\circ}$ & $888.4 \mathrm{~km}$ & $11.2 \mathrm{~m} \mathrm{~s}^{-1}$ & 2.2 \\
Santa Teresa-Birmingham & $31.3^{\circ}$ & $1878 \mathrm{~km}$ & $15.6 \mathrm{~m} \mathrm{~s}^{-1}$ & 1.6 \\
Fort Worth - Birmingham & $10.7^{\circ}$ & $989.2 \mathrm{~km}$ & $24.1 \mathrm{~m} \mathrm{~s}^{-1}$ & 1.0 \\
\hline
\end{tabular}

\subsection{Comparison with NCEP/NCAR reanalysis data}

In order to confirm the wave propagation parameters estimated by radiosonde data, we use the National Centers for Environmental Prediciton/National Center for Atmospheric Research (NCEP/NCAR) reanalysis data (Kalnay et al., 1996). The NCEP/NCAR reanalysis data are provided by the NOAA/OAR/ESRL PSD, Boulder, Colorado, USA, from their Web site at http://www.esrl.noaa.gov/psd/. This reanalysis data offers good horizontal $\left(2.5^{\circ} \times 2.5^{\circ}\right)$, but relative low vertical resolution (17 pressure levels). Since vertical resolution is not suitable for us to analyse the wave vertical structure, we did not calculate the vertical wavelength here. To fit the latitudes of five radiosonde stations, we just chose the data of daily temperature, zonal and meridional winds at $32.5^{\circ} \mathrm{N}$ to analyse.

From Fig. 8, we get the quasi 16-day wave propagation parameters in the troposphere during 15 January 2001 to 15 February 2001. The zonal wavenumber and propagation direction are estimated from the meridional wind component. Considering the meridional wind amplitudes reach maximum near $12 \mathrm{~km}$, which is near the pressure of $200 \mathrm{hPa}$, the meridional wind disturbances are fitted by harmonic analysis at $200 \mathrm{hPa}$ along $32.5^{\circ} \mathrm{N}$ and the results of amplitude and phase are shown in Fig. 10. The amplitudes at $32.5^{\circ} \mathrm{N}$ are large and basically greater than $5 \mathrm{~m} \mathrm{~s}^{-1}$, with maximum value of $13.9 \mathrm{~m} \mathrm{~s}^{-1}$. The phases decrease from west to east and totally oscillate 6 periods along the whole latitude, which means the 16-day wave propagates eastward with zonal number 6 . It is consistent with the results of radiosonde data. The amplitude and phase errors are small and almost less than $0.25 \mathrm{~m} \mathrm{~s}^{-1}$ and $4.4^{\circ}$. The blue dotted lines represent the longitudes of $115.0^{\circ}, 242.5^{\circ}, 252.5^{\circ}, 262.5^{\circ}$ and $272.5^{\circ}$ from west to east, which are the nearest longitudes of the five radiosonde stations. At these five positions, the amplitudes are $10.8 \mathrm{~m} \mathrm{~s}^{-1}, 9.5 \mathrm{~m} \mathrm{~s}^{-1}, 13.7 \mathrm{~m} \mathrm{~s}^{-1}, 10.5 \mathrm{~m} \mathrm{~s}^{-1}$ and $8.7 \mathrm{~m} \mathrm{~s}^{-1}$, while the phases are $290.0^{\circ}, 227.7^{\circ}, 175.3^{\circ}, 120.0^{\circ}$ and $40.8^{\circ}$ from west to east. It is also similar with the amplitudes and phases received from the radiosonde data. We also calculated the temperature and zonal wind at $200 \mathrm{hPa}$ (not shown), but did not find regular oscillations like meridional wind. It may indicate that the activities of planetary waves among the three components are not always the same.

In the stratosphere, the zonal wind disturbances at $10 \mathrm{hPa}$ during December 2000 are harmonic fitted (see Fig. 11). Although we lack the radiosonde data at Wuhan station, NCEP/NCAR reanalysis data shows the complete structure of a 16-day wave in the stratosphere. In Fig. 11, the amplitudes are around $5 \mathrm{~m} \mathrm{~s}^{-1}$ with peak value of $11.9 \mathrm{~m} \mathrm{~s}^{-1}$. The phases increase from west to east and totally oscillate 2 periods along the whole latitude, which means the 16day wave propagates westward with zonal number 2 . It is also consistent with the results from radiosonde data. Moreover, the phases in the west period increase slower than those in the east period. The amplitude and phase errors are small with maximum values of $0.26 \mathrm{~m} \mathrm{~s}^{-1}$ and $6.3^{\circ}$. The 

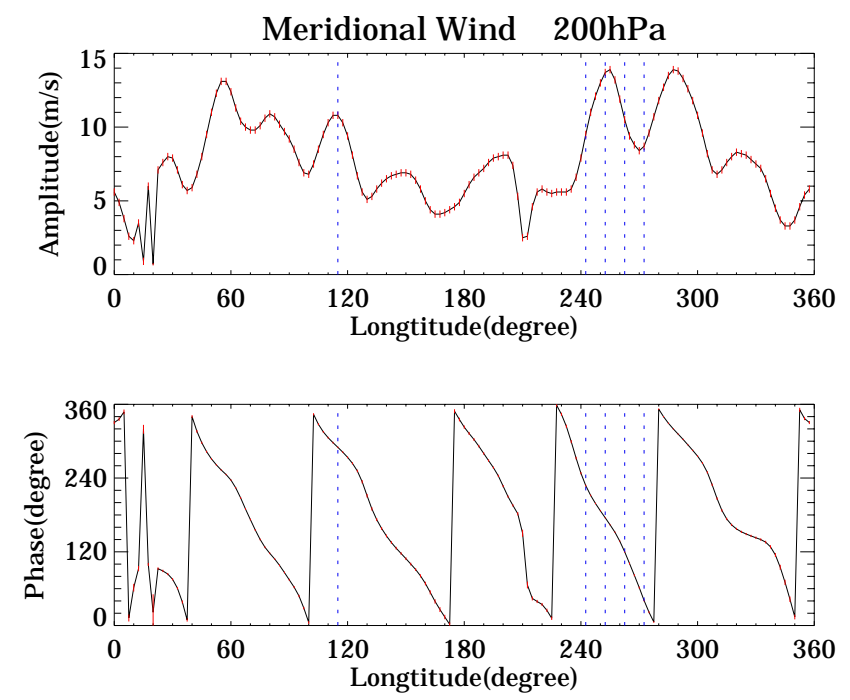

Fig. 10. The harmonic fitting results for the quasi 16-day waves of meridional wind disturbance at $200 \mathrm{hPa}$ and latitude $32.5^{\circ} \mathrm{N}$ during 15 January 2001 to 15 February 2001. The blue dotted lines in every panel denote the positions of Wuhan, Miramar Nas, Santa Teresa, Fort Worth and Birmingham from left to right. The red lines in every $2.5^{\circ}$ in longitude denote the error bar.

$10 \mathrm{hPa}$ amplitudes at four American stations are $6.0 \mathrm{~m} \mathrm{~s}^{-1}$, $6.6 \mathrm{~m} \mathrm{~s}^{-1}, 5.6 \mathrm{~m} \mathrm{~s}^{-1}$ and $8.1 \mathrm{~m} \mathrm{~s}^{-1}$, while the phases are $136.2^{\circ}, 176.3^{\circ}, 202.3^{\circ}$ and $210.1^{\circ}$ from west to east. Although the amplitudes and phase differences between the two data are different, the 16-day wave propagation parameters are similar between radiosonde data and NCEP/NCAR reanalysis data.

\section{Conclusions}

Using the radiosonde dataset between 2000 and 2004 from the United States SPARC data center and Wuhan Center Station of Meteorology in China, we studied the characteristics of the mid-latitude PWs in the TLS over America and China in this paper.

The statistics indicate that strong PW activities exist in two regions; one is in the troposphere and the other is in the stratospheric zonal wind component in winter. In the troposphere, the PWs are robust in winter and weak in summer. The amplitudes of zonal and meridional winds are roughly equal and large near the centre of the subtropical jet stream, while the temperature amplitude becomes small near the wind amplitudes maximum. That is to say, the activities of PWs in the troposphere are strong near the subtropical jet stream, which indicates the subtropical jet stream may not hinder, but strengthen the propagation of PWs, and may even be the excitation source of PWs. But towards tropopause, the amplitudes of PWs become small. It seems that the structure of temperature would also change the propagation of
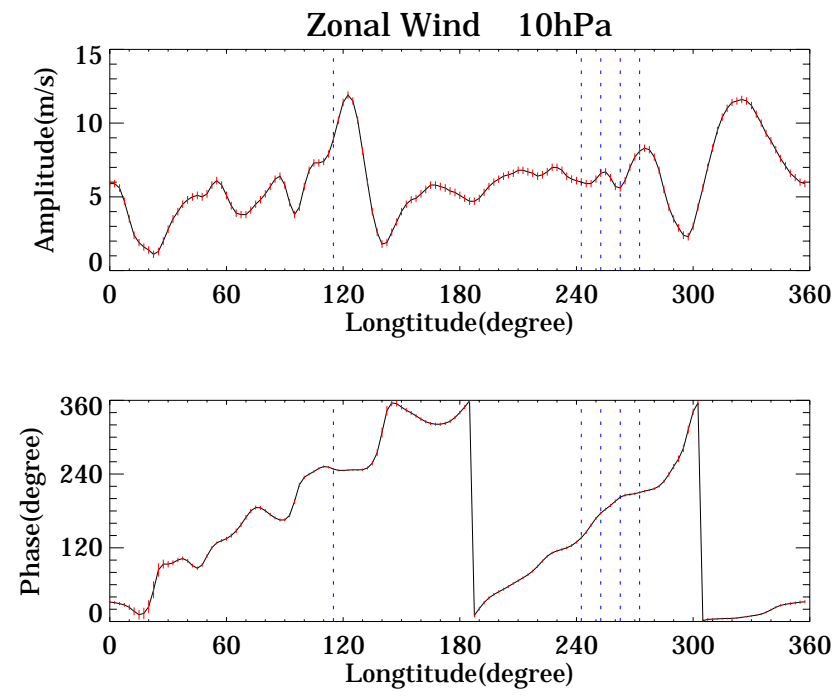

Fig. 11. Similar to Fig. 10., but for zonal wind disturbance at $10 \mathrm{hPa}$ during December 2000.

PWs. Moreover, although 5-, 10-, and 16-day waves could be found in the troposphere, it is different among the three components. In the temperature component, the low-frequency planetary waves are stronger and more common at Wuhan than at the four American stations, while the planetary waves in the zonal wind component at Wuhan are weaker. As to meridional wind component, the strength of spectral amplitude at Wuhan is the smallest, while the amplitude at Miramar Nas is the largest. And the amplitudes at the four American stations decrease from west to east. However, in the stratosphere, only lower frequency PWs appear in winter. And among the three components, strong PWs mainly exist in the zonal wind component. The amplitudes of the PWs increase with height, but the values are smaller than those in the troposphere. It indicates that the low frequency waves can propagate upward in winter with some energy being absorbed or dissipated. By calculating the refractive index, it is found that whether the PWs could propagate upward to the stratosphere depends on the thickness of the tropopause reflection layer. Since the tropopause reflection layer is thin in winter and thick in summer, it is difficult for PWs to propagate upward in summer. In addition, the subtropical jet stream, the possible excitation source, is weak in summer. So although there are better conditions for propagations of PWs in summer, fewer PWs are found in the stratosphere.

The case study shows that in the 2000/2001 winter, there are quasi 16-day waves both in the troposphere and the stratosphere. According to the harmonic fitting analysis in the two regions, the quasi 16-day in the troposphere is a quasi standing wave in the vertical direction and propagates upward slowly, with vertical wavelength greater than $24 \mathrm{~km}$ in the meridional component. Moreover, the tropospheric quasi 16-day wave propagates eastward with the zonal number 
between 5 and 8 . In addition, it is exciting to find that the quasi 16-day wave at Wuhan is probably the same quasi 16day wave appears at Miramar Nas, Santa Teresa and Fort Worth which propagates along the latitude stably. The quasi 16-day in the stratosphere is also a standing wave in the vertical direction with vertical wavelength larger than $10 \mathrm{~km}$. And the quasi 16-day wave is westward with the zonal number 12. However, there are many differences between the two quasi 16-day waves, so the quasi 16-day wave in the stratosphere is not likely to come from the quasi 16-day wave in the troposphere. NCEP/NCAR reanalysis data are used to compare with the results of quasi 16-day wave propagation parameters in the troposphere and stratosphere. It is found that although the five radiosonde stations are sparse to estimate zonal propagation characteristics, our estimations with radiosonde data and NCEP/NCAR reanalysis data match well with results of directions of zonal propagation and zonal wavenumbers in the troposphere and stratosphere.

Acknowledgements. We are grateful to the United States SPARC data center for providing the radiosonde data without charge, and we thank NOAA/OAR/ESRL PSD for providing NCEP Reanalysis data freely. We also sincerely thank the anonymous reviewers for their valuable suggestions on this paper. This work was jointly supported by the Specialized Research Fund for State Key Laboratories; Ocean Public Welfare Scientific Research Project; the National Natural Science Foundation of China (grant Nos. 41004064, 40825013 and 40974082); and the National Basic Research Program of China (grant 2012CB825605).

Topical Editor C. Jacobi thanks D. Pancheva and one anonymous referee for their help in evaluating this paper.

\section{References}

Alexander, M. J.: Interpretations of observed climatological patterns stratospheric gravity wave variance, J. Geophys. Res., 103, 8627-8640, 1998.

Alexander, S. P. and Tsuda, T.: Observations of the diurnal tide during seven intensive radiosonde campaigns in Australia and Indonesia, J. Geophys. Res., 113, D04109, doi:10.1029/2007JD008717, 2008.

Allen, S. J. and Vincent, R. A.: Gravity-wave activity in the lower atmosphere: Seasonal and latitudinal variations, J. Geophys. Res., 100, 1327-1350, 1995.

Andrews, D. G., Holton, J. R., and Leovy, C. B.: Middle Atmospheric Dynamics, Academic Press, San Diego, 1987.

Beard, A. G., Williams, P. J. S., Mitchell, N. J., and Muller, H. G.: A spectral climatology of planetary waves and tidal variability, J. Atmos. Solar-Terr. Phys., 63, 801-811, 2001.

Charney, J. G. and Drazin, P. G.: Propagation of planetary-scale disturbances from the lower into the upper atmosphere, J. Geophys. Res., 66, 83-109, 1961.

Chen, W. and Huang, R. H.: The Propagation and transport effect of planetary waves in the northern hemisphere winter, Adv. Atmos. Sci., 19, 1113-1126, 2002.
Chen, P. and Robinson, W. A.: Propagation of planetary wave between the troposphere and stratosphere, J. Atmos. Sci., 49, 25332545, 1992.

Dickinson, R. E.: Planetary Rossby waves propagating vertically through weak westerly wind wave guides, J. Atmos. Sci., 25, 984-1002, 1968.

Hocke, K.: Phase estimation with the Lomb-Scargle periodogram method, Ann. Geophys., 16, 356-358, 1998.

Holton, J. R., Alexander, M. J., and Boehm, M. T.: Evidence for short vertical wavelength Kelvin waves in the department of energy-atmosphere radiation measurement Nauru99 radiosonde data, J. Geophys. Res., 106, 125-129, 2001.

$\mathrm{Hu}$, Y. and Tung, K. K.: Interannual and decadal variations of planetary wave activity, stratospheric cooling, and northern hemisphere annular mode, J. Climate, 15, 1659-1673, 2002.

Huang, C. M., Zhang, S. D., and Yi, F.: Intensive radiosonde observations of the diurnal tide and planetary waves in the lower atmosphere over Yichang $\left(111^{\circ} 18^{\prime} \mathrm{E}, 30^{\circ} 42^{\prime} \mathrm{N}\right)$, China, Ann. Geophys., 27, 1079-1095, doi:10.5194/angeo-27-1079-2009, 2009.

Innis, J. L. and Klekociuk, A. R.: Planetary wave and gravity wave influence on the occurrence of polar stratospheric clouds over Davis station, Antarctica, seen in lidar and radiosonde observations, J. Geophys. Res., 111, D22102, doi:10.1029/2006JD007629, 2006.

Innis, J. L., Klekociuk, A. R., and Vincent, R. A.: Interstation correlation of high-latitude lower-stratosphere gravity wave activity: Evidence for planetary wave modulation of gravity wave over Antarctica, J. Geophys. Res., 109, D17106, doi:10.1029/2004JD004961, 2004.

Kalnay, E., Kanamitsu, M., Kistler, R., Collins, W., Deaven, D., Gandin, L., Iredell, M., Saha, S., White, G., Woollen, J., Zhu, Y., Chelliah, M., Ebisuzaki, W., Higgins, W., Janowiak, J., Mo, K. C., Ropelewski, C., Wang, J., Leetmaa, A., Reynolds, R., Jenne, R., and Joseph, D.: NCEP/NCAR 40-year reanalysis project, B. Am. Meteorol. Soc., 77, 437-471, 1996.

Li, Q., Graf, H.-F., and Giorgetta, M. A.: Stationary planetary wave propagation in Northern Hemisphere winter - climatological analysis of the refractive index, Atmos. Chem. Phys., 7, 183200, doi:10.5194/acp-7-183-2007, 2007.

Lomb, N. R.: Least-squares frequency analysis of unequally spaced data, Ap. Space Sci., 39, 447-462, 1976.

Lu, X., Zhang, S. D., and Yi, F.: Radiosonde observation of planetary waves in the lower atmosphere over central China, Chin. J. Space Sci., 25, 529-535, 2005.

Luo, Y., Manson, A. H., Meek, C. E., Meyer, C. K., Burrage, M. D., Fritts, D. C., Hall, C. M., Hocking, W. K., MacDougall, J., Riggin, D. M., and Vincent, R. A.: The 16-day planetary waves: multi-MF radar observations from the arctic to equator and comparisons with the HRDI measurements and the GSWM modelling results, Ann. Geophys., 20, 691-709, doi:10.5194/angeo20-691-2002, 2002a.

Luo, Y., Manson, A. H., Meek, C. E., Thayaparan, T., MacDougall, J., and Hocking, W. K.: The 16-day wave in the mesosphere and lower thermosphere simultaneous observations at Saskatoon $\left(52^{\circ} \mathrm{N}, 107^{\circ} \mathrm{W}\right)$ and London $\left(43^{\circ} \mathrm{N}, 81^{\circ} \mathrm{W}\right)$, Canada, J. Atmos. Sol.-Terr. Phys., 64, 1287-1307, 2002 b.

Matsuno, T.: Vertical propagation of stationary planetary waves in the winter Northern Hemisphere, J. Atmos. Sci., 27, 871-883, 1970. 
Mitchell, N. J., Middleton, H. R., Beard, A. G., Williams, P. J. S., and Muller, H. G.: The 16-day planetary wave in the mesosphere and lower thermosphere, Ann. Geophys., 17, 1447-1456, doi:10.1007/s00585-999-1447-9, 1999.

Nodzu, M. I., Ogino, S.-Y., Tachibana, Y., and Yamanaka, M. D.: Climatological description of seasonal variations in lowertropospheric temperature inversion layers over the Indochina Peninsula, J. Climate, 19, 3307-3319, 2006.

Pfenninger, M. A., Liu, A. Z., Papen, G. C., and Gardner, C. S.: Gravity wave characteristics in the lower atmosphere at South Pole, J. Geophys. Res., 104, 5963-5984, 1999.

Salby, M. L.: Rossby normal modes in nonuniform background configurations. Part I: simple fields, J. Atmos. Sci., 38, 1803-1826, 1981a.

Salby, M. L.: Rossby normal modes in nonuniform background configurations. Part II: Equinox and solstice conditions, J. Atmos. Sci., 38, 1827-1840, 1981b.

Salby, M. L.: Survey of planetary-scale traveling waves: The state of theory and observations, Rev. Geophys., 22, 209-236, 1984.

Scargle, J. D.: Studies in astronomical time series analysis II: statistical aspects of spectral analysis of unevenly spaced data, Astrophys. J., 263, 835-853, 1982.

Seidel, D. J. and Randel, W. J.: Variability and trends in the global tropopause estimated from radiosonde data, J. Geophys. Res., 111, D21101, doi:10.1029/2006JD007363, 2006.

Seidel, D. J., Free, M., and Wang, J.: Diurnal cycle of upper-air temperature estimated from radiosondes, J. Geophys. Res., 110, D09102, doi:10.1029/2004JD005526, 2005.

Shimizu, A. and Tsuda, T.: Characteristics of Kelvin waves and gravity waves observed with radiosondes over Indonesia, J. Geophys. Res., 102, 26159-26171, 1997.

Tsuda, T., Murayama, Y., Wiryosumarto, H., Harijono, S. W. B., and Kato, S.: Radiosonde observations of equatorial atmosphere dynamics over Indonesia, 1, Equatorial waves and diurnal tides, J. Geophys. Res., 99, 10491-10505, 1994a.

Tsuda, T., Murayama, Y., Wiryosumarto, H., Harijono, S. W. B., and Kato, S.: Radiosonde observations of equatorial atmosphere dynamics over Indonesia, 2, Characteristics of gravity waves, J. Geophys. Res., 99, 10506-10516, 1994b.

Tsuda, T., Nakamura, T., Shimizu, A., Yoshino, T., Harijono, S. W. B., Sribimawati, T., and Wiryosumarto, H.: Observations of diurnal oscillations with a meteor wind radar and radiosondes in Indonesia, J. Geophys. Res., 102, 26217-26224, 1997.

Vial, F., Hertzog, A., Mechoso, C. R., Basdevant, C., Cocquerez, P., Dubourg, V., and Nouel, F.: A study of the dynamics of the equatorial lower stratosphere by use of ultra-long-duration balloons, 1. planetary scales, J. Geophys. Res., 106, 22725-22743, 2001.
Vincent, R. A. and Alexander, M. J.: Gravity waves in the tropical lower stratosphere: An observational study of seasonal and interannual variability, J. Geophys. Res., 105, 17971-17982, 2000.

Wang, L. and Geller, M. A.: Morphology of gravity-wave energy as observed from 4 years (1998-2001) of high vertical resolution U.S. radiosonde data, J. Geophys. Res., 108, 4489, doi:10.1029/2002JD002786, 2003.

Wang, L., Geller, M. A., and Alexander, M. J.: Spatial and temporal variations of gravity wave parameters, Part I: Intrinsic frequency, wavelength, and vertical propagation direction, J. Atmos. Sci., 62, 125-142, 2005.

Wang, R., Zhang, S. D., and Yi, F.: Radiosonde observations of high-latitude planetary waves in the lower atmosphere, Sci. China Ser. D-Earth Sci., 53, 919-932, 2010.

Yang, S., Lau, K.-M., and Kim, K.-M.: Variations of the East Asian Jet Stream and Asian-Pacific-American winter climate anomalies, J. Climate, 15, 306-325, 2002

Yoshiki, M. and Sato, K.: A statistical study of gravity waves in the polar regions based on operational radiosonde data, J. Geophys. Res., 105, 17995-18011, 2000.

Zhang, S. D. and Yi, F.: A statistical study of gravity waves from radiosonde observations at Wuhan $\left(30^{\circ} \mathrm{N}, 114^{\circ} \mathrm{E}\right)$ China, Ann. Geophys., 23, 665-673, doi:10.5194/angeo-23-665-2005, 2005.

Zhang, S. D. and Yi, F.: Latitudinal and seasonal variations of inertial gravity wave activity in the lower atmosphere over central China, J. Geophys. Res., 112, D05109, doi:10.1029/2006JD007487, 2007.

Zhang, S. D., Huang, C., and Yi, F.: Radiosonde observations of vertical wave number spectra for gravity waves in the lower atmosphere over Central China, Ann. Geophys., 24, 3257-3265, doi:10.5194/angeo-24-3257-2006, 2006.

Zhang, S. D., Yi, F., Huang, C. M., and Chen, Z. Y.: Intensive radiosonde observations of gravity waves in the lower atmosphere over Yichang $\left(111^{\circ} 18^{\prime}\right.$ E, $\left.30^{\circ} 42^{\prime} \mathrm{N}\right)$, China, Ann. Geophys., 26, 2005-2018, doi:10.5194/angeo-26-2005-2008, 2008.

Zhang, Y. H., Zhang, S. D., and Yi, F.: Intensive radiosonde observations of lower tropospheric inversion layers over Yichang, China, J. Atmos. Sol.-Terr. Phys., 71, 180-190, 2009.

Zink, F. and Vincent, R. A.: Wavelet analysis of stratospheric gravity wave packets over Macquarie Island, 1 . Wave parameters, J. Geophys. Res., 106, 10275-10288, 2001a.

Zink, F. and Vincent, R. A.: Wavelet analysis of stratospheric gravity wave packets over Macquarie Island, 2. Intermittency and mean-flow accelerations, J. Geophys. Res., 106, 10289-10297, $2001 b$. 